\title{
La Comunicación No Verbal como asignatura en Filologías Clásicas y Modernas
}

\author{
Fernando POYATOS \\ Universidad de New Brunswick, Canadá \\ poyatos@unb.ca
}

Recibido: enero 2012

Aceptado: diciembre 2012

\section{RESUMEN}

El actual desarrollo interdisciplinar de los estudios de Comunicación No Verbal justifica la implementación de una asignatura que enriquezca de manera realista las perspectivas lingüísticas, literarias, artísticas y socioculturales de los programas de Filología Moderna o Clásica. Cada uno estudia la historia de su lengua, su evolución fonética y morfológica y sus distintas hablas, pero sin considerar los posibles cambios y distribución geográfica de sus repertorios paralingüísticos y (más trazables) kinésicos, ambos ampliamente descritos o implícitos en su literatura o literaturas. También se estudian la civilización, cultura y artes abarcados por cada lengua, pero sin aprovechar sus riquísimas fuentes de comunicación no verbal, sobre todo (además de la pintura antigua en Clásicas) en los períodos barroco, realista y naturalista y realismo social contemporáneo, con representaciones visuales de posturas, gestos y maneras descritos en los textos literarios de cada época (y especialmente confirmados por el realismo de los mejores ilustradores del XIX coetáneos de sus autores). Pero las perspectivas literarias en Filología Moderna se amplían con el realismo social de la fotografía de cada cultura. Como especialista multidisciplinar en Comunicación No Verbal, el autor ofrece (en su debido orden y con la bibliografía necesaria) todos los temas que abarca esta asignatura, resumiendo (e ilustrando literariamente) los temas centrales y enumerando los que socioculturalmente son también insoslayables dentro de la lingüística y la literatura, a saber: la identificación exhaustiva de los elementos no verbales contenidos en un texto; los niveles profundos de la interacción personal y con el entorno, explícitos e implícitos en los diversos géneros literarios, sobre todo novela y teatro; la estructura de la conversación representada en los dos últimos; el 'acto de lectura' y la interacción sensorial e intelectual con el libro impreso (frente a medios informáticos); el itinerario semióticocomunicativo del personaje y su entorno entre escritor (creador) y lector (recreador) y su condicionamiento personal y cultural; la percepción de los repertorios no verbales de los personajes por el lector nativo o (en traducción lingüístico-cultural) extranjero; y el fructífero enfoque diacrónico y sincrónico que nos ofrece la 'antropología literaria'.

Palabras clave: comunicación no verbal, Filologías Modernas y Clásica, enfoque sociocultural. 


\section{Nonverbal Communication as a Course in Classical and Modern Philology Programs}

\section{ABSTRACT}

The current interdisciplinary development of Nonverbal Communication Studies justifies the curricular implementation of a course which would realistically enrich the linguistic, literary, artistic and socio-cultural perspectives in the teaching of Modern or Classical Philology. Each of its branches studies the history of its language and its phonetic and morphological development and different speech areas, but without considering the possible changes and geographical distribution of its paralinguistic and (more traceable) kinesic repertoires, amply described or implicit in its literature or literatures. They also study the civilization, the culture and the arts covered by each language, yet without benefiting from its rich sources of nonverbal communication, especially (besides painting in Classic Philology) in the Baroque, Realistic and Naturalistic periods and contemporary Social Realism, with visual representations of postures, gestures and manners described in the literary texts of each period (confirmed particularly by graphic illustrators contemporaneous with their writers). But the literary realm in Modern Philology is also enriched by the photographic social realism of each culture. As an interdisciplinary specialist in Nonverbal Communication, the author offers (in due order and referring to the needed resources) all the topics for the proposed course, summarizing (with literary illustrations) its core areas and itemizing the ones that are also socio-culturally indispensable within linguistics and literature, namely: the exhaustive identification of nonverbal elements contained in a text; the deep levels of personal and environmental interaction, explicitly or implicitly shown in the different literary genres, particularly novel and theater; the structure of conversation shown in the latter two; the 'reading act' and the sensory and intellectual interaction with the printed book (vs. electronic devices); the semiotic-communicative itinerary of characters and their environment between writer (creator) and reader (re-creator) and their personal and cultural conditioning; the perception of the characters' nonverbal repertoires by native or (as linguistic-cultural translation) foreign readers; and the fruitful synchronic and diachronic approaches afforded by 'literary anthropology'.

Keywords: nonverbal communication, Modern and Classical Philology, socio-cultural approach.

\section{La communication non verbale comme matière dans les Philologies mo- dernes ou classiques}

\section{RESUME}

Le développement interdisciplinaire actuel des études de la Communication no verbale justifie l'implantation d'une matière qui enrichira de façon réaliste les perspectives linguistiques, littéraires, artistiques et socioculturelles des études de Philologie moderne ou classique. On y étudie l'histoire de sa propre langue, son évolution phonétique et morphologique, et ses différents parlers, mais on ne considère pas les changements possibles et la distribution géographique de ses répertoires paralinguistiques et (plus traçables) kinésiques, tous deux amplement décrits ou implicites dans cette littérature ou ces littératures. On y étudie aussi la civilisation, la cultures et les arts embrassés par chaque langue, mais sans 
profiter de la richesse des sources de communication non verbale, surtout (en plus de la peinture ancienne pour les philologies classiques) dans les époques baroque, réaliste, naturaliste et réalisme social contemporain, avec des représentations visuelles de postures, de gestes, et de manières décrites dans les textes littéraires de ces époques (et spécialement confirmées par le réalisme des meilleurs illustrateurs du $\mathrm{XIX}^{\mathrm{e}}$ contemporains de ses auteurs). Ainsi, les perspectives littéraires en philologie s'élargissent avec le réalisme social de la photographie de chaque culture. En tant que spécialiste en communication non verbale, l'auteur offre (dans l'ordre requis et avec la bibliographie essentielle) tous les sujets traités par cette matière, synthétisant (et illustrant littérairement) les thèmes fondamentaux et énumérant ceux qui sont socio culturellement incontournables dans la linguistique et la littérature, à savoir : l'identification exhaustive des éléments non verbaux contenus dans un texte ; les niveaux profonds de l'interaction personnelle et avec le contexte, explicites ou implicites dans les divers genres littéraires, surtout dans le roman et le théâtre ; la structure de la conversation y représentée ; «l'acte de lecture » et l'interaction sensorielle et intellectuelle avec le livre imprimé (par contraste avec les appareils informatiques); l'itinéraire sémiotique-communicatif du personnage et son contexte entre écrivain (créateur) et lecteur (recréateur) et leur conditionnement personnel et culturel ; la perceptions des répertoires non verbaux des personnages par le lecteur natif ou (en traduction linguistique-culturelle) étranger; et l'approche fructifère diachronique et synchronique offerte par « l'anthropologie littéraire.

Mots-clé: communication non verbale, Philologie moderne et classique, approche socioculturelle.

SUMARIO: 1. Integración interdisciplinar de filologías clásicas y modernas. 2. La naturaleza triple de nuestro hablar. 3. El paralenguaje. 4. La kinésica, a. Percepción sensorial y categorías. 5. La kinésica, b. Otros aspectos obligados de su estudio. 6. La kinésica, c. La mirada y la sonrisa. 7. La cara hablante. 8. Relaciones básicas de los sistemas no verbales con el lenguaje. 9. Las diez realizaciones del lenguaje verbal, el paralenguaje y la kinésica. 10. Los silencios y sus funciones comunicativas. 11. La transcripción realista del discurso verbal-no verbal. 12. El 'uso' verbal y no verbal y el fondo condicionante de nuestro discurso. 13. El modelo de las categorías no verbales. 14. Inventarios kinésicos en las filologías modernas. 15. La literatura como fuente de documentación: presencia explícita e implícita de paralenguaje y kinésica. 16. Aspectos insoslayables de lo no verbal relacionados con la literatura. 17. La pintura, la ilustración y la fotografía en los programas de filología. Referencias bibliográficas

\section{INTEGRACIÓN INTERDISCPLINAR DE FILOLOGÍAS CLÁSICAS Y MODERNAS}

1.1. Desde los últimos años 60 , impulsado por una licenciatura y un doctorado en Filología Inglesa, y bastantes años de vida académica como hispanista (descubriendo mis grandes lagunas si prescindía de la inmensa riqueza 'no verbal' de nuestra lengua y su literatura), he procurado avanzar los entonces jóvenes estudios de Comunicación No Verbal, en publicaciones, ponencias, conferencias plenarias o inaugurales y simposios y secciones de congresos que organizaba en lingüística, comunicación, antropología y etnología, psicología, semiótica y literatura; y en 
España, y una veintena de países hasta ahora, en facultades y departamentos de estos y otros campos (ej., Traducción, Interpretación, Comercio, Teatro, Musicología, Enfermería, Publicidad, Enseñanza de Lenguas Extranjeras, Hostelería). Ante las sorprendentes lagunas en esas disciplinas, he fomentado nuevas perspectivas en cada uno de ellas, casi siempre interdisciplinarmente (ej., Poyatos, 2000). Por otra parte, los programas de los cursos sobre Comunicación No Verbal que impartí durante los últimos veinte años en los departamentos de Antropología, Sociología y Psicología de mi Universidad, han aparecido, con diversas actualizaciones, en algunos de mis libros (ej., Poyatos, 1983, 1988, 2002a). Pero en bastantes ocasiones me he encontrado hablando para profesores y alumnos de un departamento de Filología Hispánica, Inglesa o Románica, o de Psicología, cuando era aplicable igualmente a otras especialidades. Por eso he sugerido siempre la integración de la Comunicación No Verbal en los currículos de Lingüística y de Filología moderna o clásica (y, por supuesto, la del propio idioma) - y últimamente, en esta revista, en la enseñanza primaria y secundaria (Poyatos, 2012) — para concienciar a sus futuros especialistas hacia la realidad verbal-no verbal de su habla diaria (aparte de los casos de lenguas diferentes en convivencia bilingüe), compuesta básicamente, por ejemplo, en España, de la estructura triple del discurso, lenguaje verbalparalenguaje-kinésica, del habla castellana, extremeña, andaluza, riojana, etc.

Se trata, pues, de implementar una asignatura sobre lo no verbal en cada uno de los ámbitos de Filología. Pero, ¡atención!, no únicamente el paralenguaje y la kinésica, perpetuando una perspectiva miope de que adolecen tantísimos estudios, o por lo que me identifican a mí en recensiones que dejan a un lado lo mucho más que he estudiado como comunicación no verbal, que defino:

Las emisiones de signos activos o pasivos, constituyan o no comportamiento, a través de los sistemas no léxicos somáticos, objetuales y ambientales contenidos en una cultura, individualmente o en mutua coestructuración.

1.2. Los estudios de Filología se especializan, en primer lugar, en las lenguas clásicas, que llamamos "muertas", cuyos textos, hoy mudos, solo nos evocan ciertos sonidos del discurso por sus descripciones verbales y escasos símbolos puntuarios, sin acercarse a la realidad total de su existencia - cómo decían y movían lo que decían (palabras-paralenguaje-kinésica) - , que, entonces (apenas hoy) podían evocar las descripciones verbales escritas en un Satiricón o una Iliada.

A esa oferta curricular de las lenguas clásicas se añade: el estudio diacrónico de los propios idiomas (ej., Latín Vulgar, Historia de la Lengua Española) y sus 
literaturas (ej., departamentos de Inglés en los países anglosajones, ${ }^{1}$ o Filología Románica en los de habla española); y la especialización en las llamadas "filologías modernas" (ej., Alemana, Francesa, Italiana, Inglesa, Eslava, etc.). Pero el currículo para estas lenguas vivas incluye también fases de su historia, de cuya realidad audiovisual solo poseemos descripciones literarias incapaces de descubrirnos importantes detalles de la voz (paralenguaje), gestos, maneras y posturas (kinésica) simultáneos a las palabras o alternando con ellas en perfecta relación cultural e histórica, como imaginamos leyendo en el Quijote: «Decía esto con tanto brío y denuedo», o «con reposo y ademán severo». Pero en el caso de los años 30 a los 50, apreciamos hoy cambios concretos en el paralenguaje y la kinésica (especialmente gestos y posturas) por las primeras grabaciones radiofónicas y del cine sonoro, la persistencia de ciertos comportamientos, la desaparición de algunos y la aparición de otros. Es decir, que aunque hayan perdurado muchos gestos, maneras y posturas, también ha podido variar su ejecución ("cualidades parakinésicas") o la voz que pueda acompañarlos: «[...] dijo, meneando la cabeza a una parte y a otra:/ - ¡Ay señor, señor!» (Cervantes, Quijote); otros han desaparecido: «[Sancho] poniéndose el dedo pulgar en la garganta y extendiendo la mano arriba, les dio a entender que no tenía ostugo de moneda» (Cervantes, Quijote). Claro que la kinésica ha tenido históricamente sus condicionantes: vestido, moral, religión, relaciones sociales, normas de etiqueta, etc.

Por supuesto, la inclusión de un curso sobre comunicación no verbal enriquece enormemente cualquier programa realista de Lingüística General, como sugerí, por ejemplo, en un volumen compilado por el Prof. Payrató, estudioso de lo no verbal en el ámbito catalán (Poyatos, 2004); aparte de lo que esto supone para la enseñanza del propio idioma como lengua extranjera, que debe (pero solo excepcionalmente es así por ahora) proporcionar a esos hablantes (con un gran lastre nativo verbalno verbal) "fluidez verbal-no verbal", y no solo basada en palabras y estructuras gramaticales que incluya la comunicación no verbal.

1.3. En Filología Románica, y en las modernas, podemos estudiar muchas conductas no verbales audibles (lenguaje verbal y paralenguaje) y visuales (kinésica, proxémica); y, gracias a la observación directa y a las artes, los otros aspectos no verbales comportamentales y no comportamentales y del entorno cultural. Estudiamos, por ejemplo, la evolución fonética y morfológica del idioma, pero ¿quién alude a las variaciones y cambios morfológicos de sus repertorios paralingüísticos y (más trazables) kinésicos? Y eso que contamos con una amplísima documentación de lo no-verbal descrito o latente en sus literaturas:

\footnotetext{
${ }^{1}$ Mi primer libro sobre comunicación no verbal, Man Beyond Words (1976), primer intento interdisciplinar en este campo, me lo encargó precisamente, después de unas conferencias, el New York State English Council, asociación de departamentos de Filología Inglesa.
} 
el Cid del rey] reçibió las espadas las manos las besó [...] alçava la mano, a la barba se tomó;/ "por aquesta barba que nadie non mesó,/ así irán vengando doña Elvira e doña Sol" (Poema del Cid).

Et [doña Truahana] pensando en esto comenzó a reir con grand placer que avía de la su buena andança, e, en riendo, dio con la mano en su frente e entonçe cayol la olla de la miel en tierra, e quebróse (D. Juan Manuel, Conde Lucanor).

Además, en las Filologías clásicas y en las modernas se estudian la civilización y las artes de esos pueblos, fuentes riquísimas de comunicación no verbal personal (solo en lo visual) y ambiental, sobre todo desde los períodos pictóricos realistas, con imágenes de posturas y de gestos y maneras en el punto central de su ejecución, correspondientes a las descripciones que de muchos de ellos encontramos en los textos literarios. ${ }^{2}$

1.4. En cuanto a la asignatura aquí propuesta, se verá más factible una propia para cada una de las Filologías. ${ }^{3}$ Por eso, para que cualquier docente pueda elaborar su programa, aquí, siguiendo la cronología propia de un curso así, sintetizo los aspectos más indispensables, mencionando solo otros muy importantes que no deben excluirse de cada programa.

Para facilitar al máximo la preparación de un programa, al final de cada sección, bajo el epígrafe "MATERIALES", doy las referencias a los trabajos míos con los que pueden organizarse los temas en ella tratados, y de algún otros autor, pero (a fin de evitar una excesiva repetición) solo por fechas y reunidos en una bibliografía final. ${ }^{4}$

\section{LA NATURALEZA TRIPLE DE NUESTRO HABLAR}

2.1. Lo que llamamos "hablar", pues, consiste en utilizar tres canales que forman lo que en 1971 expuse como la 'basic triple structure' de la comunicación humana, o sea, del discurso: "lo que decimos" (lenguaje verbal: las palabras), "cómo lo decimos" (paralenguaje: modificaciones de la voz y tipos de voz, más las muchísimas

${ }^{2}$ Un prometedor tema de investigación, aún novedoso, es un repertorio de descripciones kinésicas literarias cotejadas con sus correspondientes imágenes artísticas.

${ }^{3}$ Como se hizo, por ejemplo, en los años 90 en el Departamento de Turismo de la Universidad de Bogazici (Estambul) después dar allí una serie de conferencias, y con el programa que yo mismo les elaboré. Si es verdad que así se pierden ciertas perspectivas comparativas que ampliarían el horizonte de los participantes, el tener que aludir a aspectos de cada Filología en una asignatura común, y utilizar ejemplos ajenos a los conocimientos e inclinaciones de cada alumnado, limitaría muy imprácticamente la aplicación de los distintos temas y ejemplos a cada especialidad.

${ }^{4}$ Aunque es de esperar que toda persona universitaria conozca suficientemente el inglés, remito más a trabajos míos en español, excepto para temas tratados más extensamente, o actualizados, en inglés. 
emisiones cuasiléxicas independientes) y "cómo lo movemos" (kinésica: gestos, maneras y posturas). Siendo realistas, hemos de reconocer: (a) esta triple realidad y, en el fluir del discurso, su doble carácter: segmentable (palabras y emisiones paralingüísticas independientes, como "Mm”, “¡Pst!”, más pausas, gestos y posturas; y no segmentable (entonación, rasgos paralingüísticos modificadores de la voz y rasgos parakinésicos de movimientos y posiciones); y (b) la capacidad de esos tres sistemas para sustituirse mutuamente dentro de un orden sintáctico y las posibles funciones verdaderamente léxicas y gramaticales del paralenguaje y la kinésica. «- ¿Hija de usted? [la enferma]/ Respondieron unos ojos llenos de lágrimas» (Espina, La esfinge maragata). ${ }^{5}$

2.2. Estudiamos primero el lenguaje verbal: una sucesión de palabras y frases, morfológicamente con un nivel segmental de vocales y consonantes, y otro suprasegmental de curvas entonativas, y con una selección léxica para conceptos "decibles", mientras que otros, que con palabras desnudas, serían inefables, "indecibles", podemos expresarlos añadiéndoles elementos paralingüísticos o kinésicos, o ambos, que no todos poseemos en la misma medida: "Sí, es algo muy...sutil" (frotando "sutilmente" los tres primeros dedos de una mano). O sea, que, por ejemplo, los elementos kinésicos que dinamizan los rasgos de un rostro, y las cualidades de la voz que recibimos a través de él, tienen el poder de lexicalizarse y expresar lo inefable.

MATERIALES. Poyatos 2003; Poyatos 1994a: Cap. 4.1-4.4, 4.6-4.8. También: Poyatos 1994a: Cap. 1.1, 1.2, 1.6; 1996a, 2000.

\section{EL PARALENGUAJE}

Nuestras palabras las acompañamos (o alternan) con el "paralenguaje", —sobre el cual escribí la única monografía existente (Poyatos, 1993) — con las cuatro categorías que he distinguido y resumo sucintamente), que he definido como:

Las cualidades no verbales de la voz y sus modificadores y las emisiones independientes cuasiléxicas, producidas o condicionadas en las zonas comprendidas en las cavidades supraglotales (desde los labios y nares hasta la faringe), la cavidad laríngea y las cavidades infraglóticas (pulmones y esófago) hasta los músculos abdominales, así como los silencios momentáneos, que utilizamos consciente o inconscientemente para apoyar o contradecir los signos verbales, kinésicos, proxémicos, químicos, dérmicos y térmicos, simultáneamente o alternando con ellos, tanto en la interacción como en la no-interacción.

\footnotetext{
${ }^{5}$ Pero esto no ocurre en un vacío semiótico, sino en relación con el comportamiento y actitudes sociales dentro del entorno objetual y natural, percibido sensorial e intelectualmente y según la cultura, nivel socioeducacional, personalidad, temperamento, estado de ánimo, etc.
} 
Cualidades primarias básicas: timbre, resonancia, volumen (tensión), tempo, tono (registros), campo entonativo, duración silábica, ritmo. «La hizo hablar [doña Paula a Teresina] para apreciar el tono de la voz [término polisémico], como el timbre de una moneda» (Alas, La Regenta), «—_Cuántas gaseosas quiere? [...]/ —Pues... [duración silábica] Que nos ponga ocho» (Sánchez Ferlosio, El Jarama).

Calificadores, tipos de voz producidos por distintos tipos de controles, por ejemplo: respiratorio (ej., espirando, aspirando, jadeante) laríngeo (ej., voz susurrante, murmurada, halitante, comprimida, estridente, metálica, ronca), esofágico (voz esofágica) faríngeo (ej. voz faringalizada, hueca, empañada), quejumbrosa, áspera, cascada, susurrante), velofaríngeo (ej., voz gangosa, gimiente), lingual (ej., voz palatalizada), labial (ej., el típico redondeamiento francés o con actitud mimosa), mandibular (ej., mascullando), articulatorio (ej., articulación confusa, lambdacismo, hiperarticulación), objetual (ej., con una pipa en la boca). «[don Quijote, agarrando a la criada de la venta en la oscuridad] Y, teniéndola bien asida, con voz amorosa y baja le comenzó a decir:--[...] fermosa y alta señora [...]» (Cervantes, Quijote).

Diferenciadores de reacciones fisiológicas - algunas reflejas, que podemos modificar paralingüística y kinésicamente con intención comunicativa- y psicológicas, que varían funcional y actitudinalmente entre culturas: risa (de afiliación, agresión, juego, adulación, ansiedad, etc.), llanto (de afiliación, dolor, gozo, etc.), gritos (de agresión, alarma, sorpresa, aprobación, etc.), suspiros (de placer, nostalgia, alivio, etc.), toses y carraspeos (solo fisiológicos o intencionalmente comunicativos para advertir, ahogar una voz, etc.), estornudos y bostezos (cultural y socialmente asociados o no a conductas verbales y no verbales controladas), incluso eructar o escupir (para incluir en inventarios, ya que pueden modificarse comunicativamente). «[Dorotea] después de haberse puesto bien en la silla y prevenídose con toser y hacer otros ademanes, con mucho donaire comenzó a decir [...]» (Cervantes Quijote), «Ella [María Rosario] suspiró angustiada como si el aire le faltase» (Valle-Inclán, Sonata de primavera).

Alternantes, verdadero vocabulario - muchos en diccionarios realistas, como el Webster) - , fomentado gráficamente por lo que he llamado "sonografías" (típicas de los cómics): chasquidos linguales, aspiraciones y espiraciones, siseos, chisteos, bisbiseos, fricciones faríngeas o nasales, gemidos, resoplidos, ronquidos, soplos, sorbos, sonidos dubitativos, etc.; a su vez modificables por rasgos kinésicos y paralingüísticos para referirse, por ejemplo, a cualidades personales (ej., "Es un tío, ¡mmmg!”, glotalizando con los labios cerrados para denotar valor o voluntad férrea), actividades: «De repente, pim... un tiro [...] nuestra gente se echa los fusiles a la cara. Ta-ta-ra-trap... Un negrazo salta sobre mí, y zás, le meto el machete por el ombligo» (Galdós, Fortunata y Jacinta).

MATERIALES. Lateiner 1992; Newbold 1992; Poyatos 1993; 1994b: Caps. 14; 2002b: Caps.1-4; 1998a. 


\section{LA KINÉSICA, A: PERCEPCIÓN SENSORIAL Y CATEGORÍAS}

Alternando o entretejido con palabras y paralenguaje, utilizamos el tercer cosistema de nuestro discurso, la kinésica, que he definido, de modo realista y exhaustivo, como:

Movimientos y posiciones de base psicomuscular conscientes o inconscientes, aprendidos o somatogénicos, de percepción visual, audiovisual y táctil o cinestésica, aislados o combinados con la estructura verbal-paralingüística y con otros sistemas somáticos y objetuales, que comunican intencionadamente o no. ${ }^{6}$

Comprende, pues, todo movimiento o posición observable: gestos, maneras, posturas, la mirada, respingos, tics y cualquier mínimo acto kinético visible, que puede ser, por ejemplo, andaluz (e.j., como "marcadiscursos", identificados más abajo). Además, siguen un desarrollo ontogénico, una estratificación social, una distribución geográfico-cultural y unos cambios sociales (por el vestido, el mobiliario, los valores morales, etc.).

Percepción sensorial. Puede ser: visual sobre todo; auditiva (ej., aplauso, significativo sonido de pasos). «Dióse don Quijote una gran palmada en la frente, y comenzó a reír muy de gana» (Cervantes, Quijote); táctil (ej., besando): «She [Mrs. Driffield] held out her hand [...] it gave mine a warm and hearty pressure» (Maugham, Cakes and Ale); cinestésica (ej., compartiendo un sofá, yendo del bracete).

Dimensión temporal. Un comportamiento kinésico puede proyectarse en el tiempo (ej., reconstruyendo la gestualidad de alguien como parte de su discurso, o cuando unas colillas nerviosamente aplastadas en un cenicero evocan cierto estado de ánimo).

Gestos. «El cabo tamborileaba con los dedos sobre el correaje, como haciendo acopio de paciencia» (Caballero Bonald, Dos dias de setiembre).

Maneras. Se trata de cómo se ejecuta un gesto o se adopta o deshace una postura, según cultura, sexo, nivel socioeducacional, estado de ánimo, etc., así como comiendo, fumando, cruzándose de piernas, rascándose, etc. «y, embrazando su adarga, asió de su lanza, y con gentil continente se comenzó a pasear delante de la pila» (Cervantes, Quijote), «el buen D. Nazario [...] terciándose el manteo [...]» (Galdós, Nazarín, II, V). ${ }^{8}$

\footnotetext{
${ }^{6}$ La definición más utilizada, según Korte (1993, 1997).

${ }^{7}$ El sentido de la cinestesia, a través de los músculos, tendones, nervios y articulaciones, nos comunica la posición de nuestro cuerpo y miembros en el espacio y con relación a todo aquello con que entremos en contacto.

${ }^{8}$ Obsérvese el valor histórico de ambos comportamientos, tema de investigación en sí independiente.
} 
Posturas. De gran valor comunicativo, intercultural, social y personal (ej., diferencias generacionales), a veces combinadas con maneras. «cada mañana oía su misa, sentadas ambas rodillas en el suelo, juntas las manos, levantadas del pecho arriba, el sombrero encima dellas» (Alemán Guzmán de Alfarache).

MATERIALES. Lateiner 1992; Poyatos 1994b: Cap. 5.1-5.3, 5.5; 2002b: Cap. 5.1-5.3, 5.10, 5,11; 1999.

\section{LA KINÉSICA, B: OTROS ASPECTOS OBLIGADOS DE SU ESTUDIO}

Las tres fases del acto kinésico: formativa, central y desarticuladora. La primera y la última manipuladas por la fotografía periodística, mientras que la central define mejor el gesto o postura, generalmente representada por las artes, fuente de datos diacrónica y sincrónica para, por ejemplo, un inventario kinésico con imágenes.

Calificadores parakinésicos, según estilos personales y culturales: los repertorios no verbales del hablante andaluz o anglo-indio, su desarrollo ontogénico, desviaciones sexuales, etc. Intensidad (tensión muscular): «Robin stirred his coffee furiously» (Wilson, Anglo-Saxon Attitudes); presión: «Ana, al darle la mano tuvo miedo de que él se atreviera a apretarla un poco» (Alas, La Regenta); campo: «arremetió a don Quijote y, abrazándole por las piernas, comenzó a llorar» (Cervantes, Quijote); velocidad: «It was a slow smile [...] a very sensual smile and it made her heart melt in her body» (Maugham, The Painted Veil); duración: «[bebiendo de las botas] meneando las cabezas a un lado y a otro [...] se estuvieron un buen rato» (Cervantes, Quijote).

Actos kinésicos libres. Por ejemplo, un /¡Adiós!/ con la mano en el aire.

Actos kinésicos trabados. Por ejemplo, /atusándose el pelo/, /abrazando/).

Coestructuración con otros sistemas de signos comunicativos. Esta puede ser: intersistémica, es decir, su relación con las palabras, el paralenguaje, el sonrojo, etc., aun en la misma frase: «Sancho [ante el moribundo don Quijote] empezó a hacer pucheros y a derramar lágrimas]»(Cervantes, Quijote); o intrasistémica, dentro de la misma kinésica: «Don Pedro se deshacía en gestos denegatorios al mismo tiempo con la cabeza y con las dos manos» (Martín Santos, Tiempo de silencio).

Kinefrases gestuales: «[don Quijote] enarcó las cejas, hinchó los carrillos, miró a todas partes, y dio con el pie derecho una gran patada en el suelo, señales todas de la ira que encerraba en sus entrañas» (Cervantes, Quijote).

Simultaneidad semántica múltiple: «seguía él hablando con expresión de caricia y de celo [...] seguro de vencer todas las dificultades» (Espina, La esfinge maragata).

Congruencia o incongruencia semántica entre diversos componentes kinésicos.

Gestos anticipatorios, característica de los gestos ilustrativos del discurso.

Gestos y maneras sonoros (fonokinésica), en contactos interpersonales (ej., palmeándose las espaldas como saludo) o con objetos (ej., un elocuente portazo intencionado), de carácter cuasi verbal y diferenciados por personalidad y cultura. 
Microkinésica, en movimientos y posiciones: microgestos (ej., una contracción muscular), micromaneras (ej., una levísima inclinación de saludo) y microposturas (ej., de los dedos sosteniendo una taza al beber, la permanente postura de los labios), rasgos personales e interactivos valorados según nuestra sensibilidad: «el tenedor [...] continuaba elevándose [...] hasta depositar, con un leve giro, el trozo de carne entre los labios, imprescindiblemente separados» (López Pacheco, Central eléctrica).

Posturas dinámicas, cuando una postura básica contiene un elemento moviente (a veces como tic): «Después [Nicolás] meditó un rato, las manos cruzadas y dando vuelta a los pulgares uno sobre otro» (Galdós, Fortunata y Jacinta).

Kinésica contactual interpersonal y con las cosas, fase más cercana de la proxémica, personal y hasta íntima, con variaciones culturales y subculturales (ej., saludos entre familiares o extraños), como en posturas contactuales, según períodos y generaciones (ej., una pareja caminando abrazados por la cintura, ella con la mano dentro del bolsillo trasero de los vaqueros de él), contactos interpersonales mediados por objetos, o contactos con objetos del entorno. ""Then stay with me a little longer," Madame Olenska said in a low tone, just touching his knee with her plumed fan. It was the lightest touch, but it thrilled him like a caress» (Wharton, The Age of Innocence).

Gestos ocultos. Son gestos (faciales, manuales) que no dejan de estar ahí (ej., de burla), aunque los demás no puedan percibirlo.

Configuración kinésica personal (repertorios propios) y hasta dialectal, siempre, excepto en anomalías clínicas, coherente con el lenguaje y el paralenguaje ${ }^{9}$ : «descubrí [...], en lo vehemente de sus meneos, en la manera como accionaba, como acompañaba con las manos, con la cabeza, con los hombros, a las palabras que le salían de la boca [...] un parecido atroz con mi tío Manolo» (Ayala, La cabeza del cordero).

MATERIALES. Newbold 1992; Poyatos 1994b: Cap. 5.4, Cap. 6.1-6.7; 2002b: Cap. 5.4-5.7, 5.13; Cap. 6.1-6.7; 2002e.

\section{LA KINÉSICA, C: LA MIRADA Y LA SONRISA}

En cada rama de Filología moderna debemos prestar íntima atención a las descripciones literarias y representaciones pictóricas de estos dos comportamientos.

Las conductas oculares (movimientos y posturas de pupilas, enmarcadas por los párpados y las pestañas, a veces por las cejas) son esenciales en la "cara hablante" (y más importantes que los gestos manuales, más obvios y estudiados) y se funden, negativa o positivamente con las palabras, el paralenguaje y otras conduc-

\footnotetext{
${ }^{9}$ Piedra de toque para confirmar una buena caracterización literaria constante en un personaje.
} 
tas kinésicas. La mirada comprende gestos, maneras y posturas, y en interacción se funde con el perfume, el sonrojo, el contacto físico, etc., y con sus propios calificadores (brillo de los ojos, lágrimas, etc.), pues muchos ojos nos parecen solo órganos de visión que 'nos miran', pero en otros la mirada parece venir de los más hondos rincones de la persona.

La sonrisa — quizá el gesto humano que más nos afecta — podemos estudiarla: en sus variaciones culturales (ej., la a veces malentedida sonrisa japonesa); en cómo inicia muchos encuentros; en cómo aparece o no en diferentes zonas de la cara - «She looked at him a while, smiling with her lips, but not with her eyes» (James, The Europeans) - o la abarca toda; cómo califica el discurso ("discurso sonreído"); cómo se funde con otras formas de expresión; o cómo cambia una primera impresión negativa de alguien.

MATERIALES. Poyatos 2002b: Cap. 5.8, 5.12; 2002d: 111.113.

\section{LA CARA HABLANTE}

He aquí otro tema imposible de resumir sin trivializarlo. La mirada es parte de la 'cara hablante', y esta constituye un tema central, sobre todo para analizar la comunicación no verbal en las diferentes literaturas: las funciones interactivas de los rasgos faciales: permanentes (estáticos), cambiantes, dinámicos y artificiales. Un estudio literario con esta múltiple perspectiva (y observando el desarrollo paralelo de la pintura) es interesantísimo en cualquiera de las ramas de Filología, abarcando, por ejemplo, todo un autor, una tendencia literaria concreta o, diacrónicamente de forma panorámica, a través de la literatura de una cultura específica.

MATERIALES. Poyatos 2002a: Cap. 3; 2008: 267-269.

\section{RELACIONES BÁSICAS DE LOS SISTEMAS NO VERBALES CON EL LENGUAJE}

Es imprescindible considerar cómo los sistemas no verbales (ej., paralenguaje, kinésica, lágrimas) pueden afectar a las palabras: (a) añadiendo información, si el gesto o el paralenguaje que precede acompaña o sigue al mensaje verbal expresando algo de lo que dice por sí solo. «Pero ¿qué quieren ustedes que les diga yo? preguntó Andrés con un acento en que se confundían la contrariedad, harto manifiesta, y el enojo muy mal disimulado» (Pereda, Sotileza); (b) apoyándolas: «Lo que Amalia me ha dicho — afirmó Jacinta con súbita ira, llena de dignidad, poniéndose en pie y afianzando con un gesto admirable su aseveración - es verdad. Yo digo que es verdad, y basta» (Galdós, Fortunata y Jacinta); (c) repitiendo lo expresado: «-Yo ya probé el vinillo y da gloria - dijo el Cuba juntando los dedos y acercándoselos a los labios» (Caballero Bonald, Dos días de setiembre); realzando su significado; (d) debilitándolas, como un 'Sí' que suena dubitativo por su alargamiento y quizá por otros rasgos paralingüísticos ('Mmmm... sí'); (e) contradiciéndolas, como ese mismo 'Sí', pero con gesto y paralenguaje que significan "¡Sí, claro, qué bien!”; (f) enmascarándolas (incluso sus calificadores paralingüísticos), 
aunque, por ejemplo, una emoción puede entreverse por una 'fuga de información': «Hacía el traidor que sus lágrimas acreditasen sus palabras y los suspiros su intención» (Cervantes, Quijote); (g) economizando su uso, cuando el gesto o la voz añaden información que evita otras palabras (ej., "Bueno.../gesto de 'por un oído le entra y por otro le sale/""); (h) por deficiencia verbal cuando realmente no se recuerda o no se conoce la palabra o palabras adecuadas ("En su despacho tiene una lámpara de ésas...toda...", acompañado del gesto que describe una lujosa 'araña').

MATERIALES. Poyatos 2002a: Cap. 2.9; 2004a: 70-72.

\section{LAS DIEZ REALIZACIONES DEL LENGUAJE VERBAL, EL PARA- LENGUAJE Y LA KINÉSICA}

Para apreciar las características de las modalidades verbales-no verbales de una zona, o elaborar inventarios del idioma sin omitir el paralenguaje ni la kinésica, debemos reconocer estas posibles realizaciones: (a) lenguaje verbal, más bien neutro, sin rasgos de voz ni movimientos significativos: un simple ‘¿Qué hora es?’; (b) lenguaje verbal-paralenguaje, su verdadero significado en la parte verbal: «No me hagas pensar en lo que quiero olvidar - replicó Santa cruz con hastío» (Galdós, Fortunata y Jacinta); (c) lenguaje verbal-kinésica, una expresión verbal siempre con un sinónimo gestual, porque se hace referencia a ese gesto o porque en esa cultura este acompaña siempre a ciertas expresiones verbales: «—¿Allí había bastante?/ — ¿Bastante de qué?/ —Bastante de comer — aclaró, llevándose hacia la boca, juntos, los formidables dedos de su mano» (Ayala, El tajo); (d) lenguaje verbal-paralenguaje-kinésica, las construcciones más características: «[don Quijote] con voz atropellada y tartamuda lengua, lanzando vivo fuego por los ojos, dijo:/ ¡Oh bellaco villano [...]i» (Cervantes, Quijote); (e) paralenguaje por sí solo (risa, alternantes): «Oyó que alguien siseaba desde la puerta [...]/ -Sss...» (Caballero Bonald, DDS, I, XII); (f) paralenguaje-lenguaje verbal, el paralenguaje mucho más significativo que la parte verbal: «—Diga./ —-No, verá, es que...» (Caballero Bonald, Dos días de setiembre); (g) paralenguaje-kinésica, cuando la primera es la parte más importante: «— ¿Sabes lo que te digo?... — gritó Fortunata con la voz ronca de despecho y dolor-. Que ya estás de más aquí» (Galdós, Fortunata y Jacinta); (h) kinésica solo, lo mejor conocido (ej., juntando los dedos apiñados y abriéndolos dos veces, para 'atestado'); (i) kinésica-paralenguaje, a menudo sin que el paralenguaje afecte al contenido semántico: «Isidora le miró con ira, y respiró fuerte apretando contra el talle el lío de ropa» (Galdós, La desheredada); (j) kinésica-lenguaje verbal, si la conducta kinésica es más significativa que las palabras: «— ¡Mira; si no te callas...! —amagaba Mauricio» (Sánchez Ferlosio, El Jarama).

Elaborando no solo inventarios, sino atlas kinésicos (con 'isokinemias'), o verbales-no verbales, a base de trabajo de campo y documentación literaria y cinematográfica, cada rama de Filología (sobre modernas) se enriquecería complementan- 
do su currículo de lengua y literatura con los temas resumidos y los que quedan al menos sugeridos.

MATERIALES. Poyatos 1994a: Cap. 4.9; 2002a: Cap. 4.10.

\section{LOS SILENCIOS Y SUS FUNCIONES COMUNICATIVAS}

En cuanto a las funciones comunicativas de los silencios, tan importantes para profundizar en el estudio de la comunicación no verbal, influyen en ellos la personalidad, la cultura y el contexto situacional. Remitiendo a la bibliografía sobre el silencio —omitiendo el obligado estudio paralelo de la quietud (ausencia de movimiento)_, mencionemos solo tres de sus funciones:

- significando por sí mismo, al faltar las palabras que esperamos, como cuando alguien no responde a nuestro saludo o pregunta (no queriendo hacerlo verbalmente o kinésicamente, o porque no nos ha oído), o cuando queremos evitar decir algo;

- como portador de la actividad precedente, muy importante porque las palabras ("¡Mentira!", "Te quiero") se prolongan y amplifican más intensamente en nuestra mente si a ellas sigue una pausa, más eficazmente que seguir hablando: «Hubo un silencio total, más profundo en contraste con el escándalo anterior» (Quiroga, Viento del norte); pero a veces debemos hacer breves silencios (ej., leyendo un cuento a niños, para darles tiempo a asimilar o imaginar lo que acabamos de leerles);

- el silencio realzado por ciertos sonidos, como la lluvia golpeando suavemente la ventana, o el reloj y la pluma ante la posible presencia del Hombre Invisible: «los únicos sonidos en la habitación eran el tic-tac del reloj y la suave estridencia de su cálamo, con prisa [la del Dr. Kemp, inquieto] (Wells, The Invisible Man).

MATERIALES. Lateiner 1992;Poyatos 1994a: Cap. 5; 2002b: Cap 7; 1996b; 1998b; 2005.

\section{LA TRANSCRIPCIÓN REALISTA DEL DISCURSO VERBAL-NO VERBAL}

Cuando fui invitado en 1976 a demostrar mi modelo en Nancy (en un proyecto de su universidad y la de Birmingham), solo lo hacía aún en tres niveles: lenguaje verbal, paralenguaje y kinésica; pero en 1995 lo expuse como aquí para un equipo del Prof. Briz, en la Universidad de Valencia. El siguiente ejemplo justifica esta propuesta:

La discusión tomaba carácter personal y agresivo [...] las tazas del café chocaban furiosas contra los platillos; don Manuel, trémulo de coraje, vertía el anisete al llevarlo a la boca; tío y sobrino alzaban la voz mucho más de lo regular, y, después de algún descompasado grito o frase dura, había instantes de armado silencio, de muda hostilidad, en que las chicas se miraban, y Nucha, con la cabeza baja, redondeaba bolitas de miga de pan, o doblaba muy despacio las servilletas de todos, deslizándolas en las anillas (Pardo Bazán, Los Pazos de Ulloa). 
En efecto, en cada encuentro pasan cosas que influyen incluso en la selección léxica, en cómo se emiten las palabras paralingüísticamente y qué gestos o posturas se usan. Lo cual nos obliga a registrar cuanto pueda relacionarse al menos con las palabras, el paralenguaje o la kinésica. Registrando solo lo verbal, la kinésica queda invisible y el paralenguaje inaudible. Además, en el ejemplo citado no se trata de indicar aparte que en un momento dado el tío "vierte el anisete", sino de "ver" cómo su acción coincide con su expresión facial y con las actividades verbales o no verbales, o ambas, de los demás participantes; hay que indicar los actos kinésicos que hacen que ese "armado silencio" esté lejos de ser un vacío; y si alguien dice algo sonriendo o riendo, transcribirlo como "lenguaje sonreído" o "lenguaje reído" (con sus rasgos paralingüísticos y kinésicos, propios del hablante o culturales), integrando esa sonrisa o risa en la transcripción; e indiquemos los elementos conversacionales que puedan definir una cultura o zona lingüística

Insistamos: (a) una transcripción no debe buscar solo "lo que ocurre" o "se dice", ni siempre la relación causa-efecto en el flujo de una interacción, porque así ocultaríamos el valor de lo no dicho (lo silenciado) o no hecho - sobre todo si se esperaba que se dijera o hiciera - y el efecto de estas conductas que nunca lo fueron en el discurso de los co-interlocutores; (b) urge elaborar inventarios o atlas verbal-paralingüístico-kinésicos, o solo kinésicos (reconociendo pérdidas, creaciones y prestamos interculturales no verbales), utilizando también la narrativa y el teatro de otros períodos. Una transcripción realista ha de mostrar la superposición de hablante(s) y oyente(s), y registrar conductas simultáneas interpersonales tan significativas como la retrocomunicación ('feedback') del oyente. Los niveles de la transcripción son, pues:

1. Transcripción ortográfica, que puede leerse rápidamente siguiendo las páginas.

2. Transcripción fonética, incluyendo los rasgos entonativos básicos y utilizando los símbolos del AFI (IPA) y otros propios que puedan necesitarse.

3. Transcripción paralingüistica, con espacios para sus cuatro categorías.

4. Transcripción kinegráfica y parakinegráfica, con símbolos propios o utilizando las kinegrafías de Birdwhistell y Kendon (Poyatos, 2002a), y distinguendo tres zonas: cara (ojos y dirección de la mirada, cejas, frente, nariz [aletas], pliegues nasolabiales, mejillas, boca, mandíbula); cabeza, tronco, piernas y pies; hombros, brazos, antebrazos, muñecas, manos, dedos solos. Los rasgos parakinésicos (intensidad campo, velocidad y duración), se anotan al principio si abarcan todo el discurso como características de la persona (ej., KT/KR para kinésica tensa/rápida), o para conductas concretas.

5. Fonokinésica, incluyendo cualquiera de los sonidos "cuasiparalingüísticos" tan elocuentes vistos más arriba (probablemente acompañando las palabras).

6. Reacciones químicas y dérmicas importantes en el encuentro: lágrimas, sudor, sonrojo palidez, etc.: «"[...] you've had an armour [...] To protect yourself against me [...]." She smiled at him. Anthony dropped his eyes, blushed and mumbled some incoherent phrase» (Huxley, Eyeless in Gaza). 
7. Notación proxémica, quizá imprescindible, incluyendo distancia y orientación interpersonales, distribución del mobiliario y características generales del entorno, y un nivel más para indicar la "configuración del encuentro" (Poyatos 2002a: 227230).

8. Otros hablantes y oyentes cuyas conductas sean más o menos importantes (retrocomunicación, interrupciones, distracciones, etc.).

9. Actividades y no-actividades contextuales o interfirientes, a veces relacionadas significativamente con ciertos elementos contextuales extrapersonales: comportamiento (un elocuente portazo intencionado, sonido de pasos, etc., si provocan reacciones no verbales), causas mecánicas (ej., el tic-tac de un reloj), el entorno natural (ej., el ulular del viento, la lluvia, el perfume), objetual (mobiliario, alfombras, libros, etc.) o construido (iluminación, música, textura, espacios arquitectónicos, etc.).

10. Notación cronémica, ${ }^{10}$ con los rasgos temporales de cualquier actividad o elemento interactivo cuya duración se considere significativa entre el principio y el fin del encuentro (ej., alargamiento notable de un gesto amargo, del sonido de la 1luvia).

11. Descripción contextual: entorno cultural; cultura de cada participante; sus características físicas y rasgos faciales (naturales o artificiales); y, al menos de modo impresionista, su personalidad, nivel socioeconómico-educacional y relación entre ellos.

MATERIALES. 1993:114-120, 196-197; 1994a: Cap. 4.12; 2002a: Cap. 5.15.4; 1996b, 227-230; 2005.

\section{EL 'USO' VERBAL Y NO VERBAL Y EL FONDO CONDICIONANTE DE NUESTRO DISCURSO}

1. En cada Filología debemos identificar el uso no verbal de cada una de las culturas del idioma estudiado. Más que utilizar únicamente términos como 'estándar', 'coloquial', 'jerga', 'vulgar', tengamos en cuenta: (a) que los grupos sociales contiguos se entrecruzan porque muchos de sus miembros, que evolucionan socioeconómica y culturalmente, están a caballo entre ambos; y (b) que hay hoy entre culturas y subculturas y regiones lingüísticas la tendencia (fomentada por los medios de comunicación) a los prestamos verbales (correctos o no) y no verbales, no solo de modo horizontal y geográficamente, sino verticalmente. Por eso es útil distinguir: estándar, es decir, los repertorios verbales, paralingüísticos y kinésicos comunes a todos los hablantes, incluso a nivel 'nacional' o 'cultural'. A la vez, los de cada grupo socioeconómico u ocupacional posee una porción de su repertorio

10 Acuñé en 1972 (en Linguistics) el hoy utilizado término chronemics, como análogo a proxémica, para indicar la conceptualización y estructuración del tiempo y como área de estudio. 
comunicativo que no comparten y que consideran extraestándar, pero adoptan en circunstancias especiales según una capacidad que parece disminuir en proporción directa a su categoría socioeconómica y educacional, igual que aumenta su tendencia a criticar ese extraestándar (a mayor capacidad y flexibilidad culturales, más se aprecian esas diferencias). Pero, aparte de la clase social, hay un infraestándar inaceptable para la mayoría de los hablantes en circunstancias normales (ej., la blasfemia, ciertos gestos obscenos). Por último, vemos hoy una creciente tendencia al refinamiento léxico ( $y$, aunque no tan obvio, paralingüístico y kinésico) que llega al ultrarrefinamiento, 'ultracorrección' o 'hiperurbanismo'. Aparte de repertorios de grupo compartidos circunstancialmente por personas de niveles distintos (ej., palabras de adolescentes).

2. Como perspectiva complementaria, entre los muchos factores determinantes de estilos personales y culturales verbales y no verbales, los más relevantes son: (a) ambiente socieconómico y educacional, por el grado de socialización y sensibilización; (b) estilo cultural general de repertorios lingüísticos, paralingüísticos, kinésicos y proxémicos comunes a toda una cultura; (c) diferencias regionales, subculturales y dialectales, que a veces determinan peculiaridades en el vocabulario, en la gestualidad y en el estilo de ciertos actividades; (d) valores religiosos (o supersticiosos) y morales, o su ausencia, reflejados a veces en conductas verbales o no verbales: «[al volcarse una botella de vino] —iAlegría! — dijo ella, y le tocaba los hombros y la frente, con las yemas mojadas en el vino-》 (Sánchez Ferlosio, El Jarama); (e) relaciones y actitudes, reflejadas en la voz, gestos y posturas entre enamorados, jefes y subordinados, etc.; (f) normas de etiqueta y buenos modales que dictan las palabras, la voz, maneras y posturas en ciertas situaciones (interesante para inventarios); (g) valores estéticos (de carácter cultural y personal) que prescriben características de lenguaje, paralenguaje y kinésica, a menudo un inconsciente y natural estilo personal y hasta de grupo: «No se deue reyr sonlocadamente con disformes visages, ni reyrse por costumbre, más que por necesidad $\gg^{11}$; $(h)$ el hablante superrefinado, que a veces cae en la afectación tanto léxica como de su voz, de su risa o de su estudiada kinésica; (i) el hablante culto medio, de repertorios verbales y no verbales simplemente estándar; (j) el hablante seudoculto, por ejemplo, el que antes hubiéramos llamado 'señorito' o 'señorita' de pueblo, en una comunidad pueblerina con la que no quiere identificarse y utiliza expresiones verbales, paralingüísticas y kinésicas más propias de ese nivel superior en el que alternan (aparte de la actual influencia léxica, positiva y negativa, por la televisión); $(k$ ) el hablante de nivel socioeducacional medio-bajo, de repertorios menos refinados; (l) el hablante de nivel socioeducacional más bajo, de más naturalidad en general y

${ }^{11}$ Gracián Dantisco, Galateo español, p 237. En F. R. Marín, Un millar de voces castizas y bien autorizadas que piden lugar en nuestro léxico. Madrid: Tipografía de la Revista de Bibliotecas, Archivos y Museos, 1920. 
menos autocontrol en los rasgos paralingüísticos (el ritmo del discurso, gritando, riendo, tosiendo, estornudando, bostezando, etc.) y kinésicos (gestos, maneras, posturas); $(m)$ los préstamos de modelos sociales (ej., los 'famosos') con influencia sobre la población media o en círculos más limitados; $(n)$ los códigos verbales y no verbales dentro de ciertos grupos sociales o ocupacionales (ej., de 'la movida' o 'el botellón', o en ciertos oficios). «la chusma le saludó como es usanza cuando una persona principal entra en la galera, diciendo: “iHu, hu, hu!” tres veces» (Cervantes, Quijote).

MATERIALES. Poyatos 1994a: Caps. 1.9, 4.10; 2002a: Caps. 1.10, 4.12.

\section{EL MODELO DE LAS CATEGORÍAS NO VERBALES}

Para muchos de los objetivos de la asignatura propuesta, del modelo de 17 categorías no verbales que he analizado en varias ocasiones deben estudiarse 5.

A. Emblemas. Gestos con equivalente verbal, y sin ambigüedad en su cultura o panculturalmente (ej., en Níger, /abarrotado/, tapando con la palma de una mano el puño vertical de la otra, muy como hoy nuestros jóvenes denotan “¡Te fastidias!”); los emblemas puros también pueden coincidir con las palabras o seguirlas: «Creo que en Madrid tiene así los amantes (juntando y separando los dedos» (Alas, La Regenta).

B. Marcadiscursos. 'Movimientos del hablar', conductas (sobre todo kinésicas) conscientes o inconscientes que puntúan y refuerzan (con movimientos de cabeza, cejas, mirada, manos y tronco) la sucesión acústico-gramatical de palabras y frases, coincidiendo con los símbolos de puntuación (a su vez gramaticales y actitudinales); sus funciones principalmente sintácticas y morfológicas - aunque el valor semántico total de una palabra o frase depende de sus coactividades paralingüísticas y kinésicas y otras conductas concurrentes - y constituyen la esencia 'visualacústica' de cada idioma, lo más sutil y difícil de identificar, definir, describir y aprender o enseñar, que puede delatar fácilmente la procedencia del hablante. Desgraciadamente, escapan a la observación y estudio tradicionales del propio idioma. «Decíalo subrayando en el aire con su enérgico dedo las palabras» (Galdós , Tormento).

C. Identificadores. Dan forma corporal, más con cara y manos, a conceptos abstractos (/absurdo/ /un no sé qué/), cualidades físicas y morales (/antipático/, /un día criminal/) y cualidades de referentes objetuales y ambientales (/durísimo/, /sofocante/): «si yo pago religiosamente mi cuota un mes tras de otro - se golpeaba con el puño la palma de la otra mano-, tengo derecho a exigir» (Caballero Bonald, Dos días de setiembre).

D. Exteriorizadores. Reacciones a la realidad presente, pasada, anticipada o imaginada de otros; a lo que nosotros u otros hemos dicho o hecho, estamos diciendo o haciendo o diremos o haremos, o hemos silenciado o no hecho, silenciamos o no hacemos, o silenciaremos o no haremos; a sucesos pasados, presentes, anticipados o imaginados; a nuestros propios fenómenos somáticos; a agentes ani- 
males y ambientales; y a experiencias estéticas y espirituales. «los que [...] cortando con algunas malas tijeras o trabajando con algún otro instrumento, tuercen la boca, sacan la lengua y hacen visajes tales» (Alemán, Guzmán de Alfarache), «alzó las cejas y abrió mucho los ojos en signo de estupefacción» (Aldecoa, El fulgor y la sangre).

E. Los alteradaptadores, debidos a la conducta proxémica, ${ }^{12}$ son el contacto físico con los demás (independientes o como parte de la estructura lenguajeparalenguaje-kinésica), según las relaciones personales, el entorno, etc. Pensemos en los saludos verbales-no verbales dentro de la cultura o culturas de cada lengua: «La niña ya está hecha una moza, dentro de poco en edad de merecer - dijo el maestro al tiempo que daba una palmadita en la cara de la niña» (López Salinas, $L a$ mina).

MATERIALES. Newbold 1992; Poyatos 1994a: Cap 6; 2002a: Cap. 6; 1986.

\section{INVENTARIOS KINÉSICOS EN LAS FILOLOGÍAS MODERNAS}

1. Sabiendo que los 'gestos' son, equivocadamente, el material casi exclusivo de la mayoría de los inventarios y 'diccionarios' kinésicos (incluyendo indiscriminadamente algunas de las maneras y hasta alguna posturas) - algunos diseñados para la enseñanza de una lengua a extranjeros-, resumamos al menos ciertas normas para fomentar la elaboración de otros más realistas, más completos y tan necesarios.

1. Selección del material. Gestos, maneras, posturas, en secciones independientes subdivididas en subtemas (ej., Comiendo: Maneras: Uso de cubiertos, de la navaja campesina, bebiendo, comiendo el pan, etc.; Posturas: diferenciadas socialmente). Además de los repertorios y fraseología gestual de cada cultura, las conductas menos obvias asociadas a ciertas actividades, etc. «los hombres [...] retorcían el culo de la bota y el chorro hilado pasaba justo entre los labios entreabiertos» (López Salinas, La mina).

2. Observación directa. La única válida, con varias modalidades aceptables en situaciones interactivas (no suscitando uno las conductas o participando uno en la conversación y a la vez observando) o no interactivas (como observador, no como participante), ambas mutuamente complementadas.

3. Fuentes. Aparte de la observación directa, las demás fuentes son: informantes; televisión, cine y vídeos; periódicos y revistas, fotografía; literatura narrativa y teatro (susceptibles de sus propios inventarios); pintura e ilustraciones literarias.

4. Clasificación del material. La única exhaustiva, alfabéticamente, es la ideológica, por temas y situaciones (ej., Saludos: de lejos, cruzándose en la calle, etc., y según circunstancias y relaciones interpersonales [estas en Poyatos 1994: 208212]), evitando las limitaciones tradicionales e incluyendo los gestos más sutiles,

${ }^{12}$ Conceptualización y estructuración del espacio en nuestras interacciones. 
como los marcadiscursos o los reguladores de la conversación. Un índice final con las palabras clave que mejor describan las entradas.

5. Ilustración. Dibujos expresivos y realistas, con líneas y flechas direccionales precisas; fotos, con la expresión facial que, aun no siendo el gesto, lo acompañe; vídeo, ideal para construcciones lingüístico-paralingüístico-kinésicas.

6. Descripción. No todo gesto, manera o postura requiere ilustración visual, pero sí una descripción verbal clara, incluyendo, si es necesario: rasgos parakinésicos; relación proxémica entre interlocutores; conducta cronémica (ej., el abrazo amistoso español, iniciado a menudo antes de su ejecución, a cierta distancia, y de duración variable); su realización más estándar; cualquier posible combinación verbal-no verbal. Ha de evitarse la ambigüedad (ej., una sola versión del abrazo citado) y las descripciones incompletas (ej., excluyendo un verdadero complejo kinesintáctico).

7. Comentario cultural. En ciertos casos (con la imprescindible fluidez cultural del investigador o con un informante hábil) debe añadirse un comentario cultural sobre el origen (historia, préstamo intercultural, etc.), nivel social o contexto situacional, frecuencia, etc., así como los casos de falsos cognados con relación a otras culturas.

MATERIALES. Poyatos 1975, 1981; 1994b: Cap. 5.6; 2002b: Cap. 5.14.

\section{LA LITERATURA COMO FUENTE DE DOCUMENTACIÓN: PRE- SENCIA EXPLÍCITA E IMPLÍCITA DE PARALENGUAJE Y KINÉSICA}

1. Los comentarios en 1972 del entonces editor de la Revista de Occidente sobre un artículo mío (Poyatos, 1972) y el premiado más tarde por la Asociación Canadiense de Hispanistas (Poyatos 1976) me confirmaban ya: la urgencia de desarrollar el estudio de lo no verbal en la literatura; que una de las perspectivas más fructíferas de la comunicación no verbal en las culturas de cada Filología, clásica o moderna era (además de observarlas en vivo en su realidad cotidiana actual y en su cine más realista) la contenida en sus literaturas; y que cualquier trabajo de campo, o los datos recogidos en pintura o cine, se enriquecían enormemente: (a) cotejándolos con los verbalmente descritos, o implícitamente sugeridos, en los textos literarios; y (b) elaborando inventarios sobre un autor, obra concreta, ${ }^{13}$ período o tendencia, susceptible de establecer perspectivas comparatistas con otras literaturas. ${ }^{14}$ Excluyendo aquí la más obvia presencia explícita del paralenguaje y la kinésica, indiquemos al menos la implícita.

1. El paralenguaje implícito en el texto literario lo percibimos:

\footnotetext{
${ }^{13}$ Poyatos 1998a y 1999 recogen, respectivamente, el paralenguaje y la kinésica contenidos en el Quijote.

14 Cada capítulo de los tres volúmenes de Poyatos 1994 y 2002 contiene una lista de posibles temas.
} 
- por la kinésica del personaje, a la que corresponden ciertos rasgos de la voz (al menos en una cultura dada, si no universalmente, y no estando demasiado alejados históricamente del personaje): «¿Si me cayera ahí...? / -No lo contabas./-iQué miedo, chico! / Hizo un escalofrío con los hombros» (Sánchez Ferlosio, El Jarama);

- identificando la conducta kinésica y su significado: «-Quita, quita — clamaba la señora con expresión de asco-iMe tomas por esas...?]» (Galdós, $L a$ desheredada);

- por la conocida correlación entre otras reacciones somáticas (ej., sonrojo, llanto) y paralenguaje, incluso culturalmente: «y derramando lágrimas en grande abundancia, le dijo:/ —Señor mío [...]» (Cervantes, Quijote);

- por el contexto situacional descrito, a veces tan específicamente cultural que solo estando muy compenetrados con la cultura estadounidense o canadiense podemos 'oír' cómo exactamente la mujer de Jay dice lo que dice, al haberse levantado inesperadamente durante la noche: «"Well, you got to eat, Jay. It'll still be chilly for hours"». She spoke as if in a church or library, because of the sleeping children, unconsciously, because of the time of night» (Agee, A Death in the Family);

- por reacciones según personalidad, circunstancias o cultura del personaje: «-Conque... - murmuró el prestamista, golpeando con ambas manos los brazos del sillón, manera ruda y lacónica de expresar lo siguiente: "Señoras mías, bastante tiempo hemos perdido en la parlamenta [...]"» (Galdós, Torquemada en la Cruz).

- para el lector nativo (o muy familiarizado con esa cultura), por los rasgos paralingüísticos evocados por las palabras, otras conductas, la situación: «-Iba a sacar una canasta de uvas, mala puñalá...» (Caballero Bonald: Dos días de setiembre).

2. La kinésica implícita en el texto la percibimos:

— por las palabras del personaje: «—iA mí? Por aquí me entra y por aquí me sale» (Sánchez Ferlosio, El Jarama) ${ }^{15}$;

- por su conducta paralingüística cuando se refleja verbalmente y con la puntuación: «—¡Mira; si no te callas...! —amagaba Mauricio» (Sánchez Ferlosio, El Jarama);

- por otra conducta kinésica, como la expresión facial que en este ejemplo imaginamos por la manual: «Se detuvo a encender un puro, dándole vueltas en la boca mientras chupaba» (Caballero Bonald Dos días de setiembre);

- por reacciones químicas: «Sancho [...], compungiéndose de manera que le vinieron las lágrimas a los ojos [...] con voz dolorida y enferma le dijo» (Cervantes, Quijote);

\footnotetext{
${ }^{15}$ Dando en los años 60 un curso de novela española a anglohablantes, tuve que aclarar, ante sus sonrisas, que se trataba de la expresión inglesa 'It goes in one ear and right out the other', que no conlleva el gesto.
} 
- por la conocida correlación entre conducta kinésica y ciertas reacciones dérmicas: «Me quedé mirando a Jane con impertinencia./ —Es usted muy buena conmigo./ Se encendieron sus mejillas un momento. Esperó a que desapareciese su rubor para contestarme» (Delibes, La sombra del ciprés es alargada);

- el buen lector, por la personalidad del personaje, si su creador nos la ha ofrecido inicialmente y ha mantenido consistentemente su 'configuración kinésica'.

MATERIALES. Poyatos 2004c: Caps. 3.5, 4.4; 2002c: Caps. 3.5, 4.4; 2013 b.

\section{ASPECTOS INSOSLAYABLES DE LO NO VERBAL RELACIONADOS CON LA LITERATURA}

He resumido ciertos aspectos no verbales solo por no incitar a su omisión, pero enumeremos los más indispensables para enriquecer una asignatura como la propuesta:

(a) la presencia explícita del paralenguaje y la kinésica;

(b) las coactividades sonoras del lenguaje (la kinésica, el entorno);

(c) la estructura de la conversación representada en la novela y en el teatro;

(d) los niveles profundos de la interacción explícitos e implícitos en novela y teatro;

(e) el 'acto de lectura', la interacción con el libro (y con ediciones concretas en cada Filología, oponiendo el disfrute sensorial e intelectual de los libros al uso de los nuevos medios informáticos) y la 'oralización' del texto;

(f) la identificación exhaustiva de los elementos no verbales contenidos en un texto y los diversos procesos sinestésicos;

(g) los tipos de visión (fóvea, macular, periférica), la percepción del texto en el libro abierto (y según las ediciones), y la puntuación como comunicación no verbal;

(h) el itinerario semiótico-comunicativo del personaje y su entorno entre escritorcreador y lector-recreador;

(i) el condicionamiento personal y cultural de ambos, esencial en cada literatura.

(j) los repertorios no verbales de los personajes literarios y su percepción por el lector nativo o extranjero ( $\mathrm{y}$ en traducción);

(k) la traducción literaria como 'traslación lingüística y cultural', amplio campo;

(l) los sonidos extrapersonales y del entorno en la literatura de cada cultura;

(m) los silencios en la literatura y sus funciones;

(n) funciones estilísticas, técnicas y comunicativas de los elementos no verbales;

(o) la comunicación no verbal en teatro y cine y las relaciones personaje-actorespectador-entorno de cada período y cultura.

(p) enfoque diacrónico y sincrónico de los elementos no verbales de una cultura a través de la metodología de lo que he estudiado como "antropología literaria".

MATERIALES. (a) Holoka 1992; Newbold 1992; Golder 1992; Poyatos 1994c: Cap. 3.1-3.4; 1994d; 2002c: Cap. 3.1-3.4; (b) 1994b: Cap 6; 2002b: Cap. 6; (c) 1994a: Cap. 7; 1998b; 2002: Cap. 7; (d) 1994b: Cap. 7; 2002b: Cap. 7; (e)1997a, 2002c: Cap. 1.9; 2008: Cap. 1; 2010b; 2013a; (f) 2002c: Cap. 1.2, 2004b; 
2010a; (g) 1994: Cap. 1.6; 2002c: Cap. 1.10; 2008: Cap. 3.1; (h) 1972;1994c: Cap. 2; 2001: 9-30; 2002c: Cap. 2.1-2.2; 2008: Cap. 3.2-3.3; (i) 1994a: Cap. 2.3-2.4; 2002c: Cap. 2.4-2-5; 2008: Cap. 2.4; (j) 2002c: Cap. 1.8; 2008: Cap. 2.1-2.5; (k) Vermeer 1992;Poyatos 1997b; 2008; (l) Newbold 1992; Poyatos 1994c: Cap. 3.7; 1994d; 2002c: Cap. 3.7; 2008: Cap. 7; (m) 1994c: Cap. 3.8; 1998b; 2002c: Cap. 3.8; (n) 1972;1994c: Cap. 6; 2002c: Cap. 6; (o) 2002c: Cap. 2.2-2.8; 2008: Cap. 41, 4.5, Caps. 5-8; 2010c (p) 1988; 1992: 237-360; 1994c: Cap. 7; 2002c: Cap. 7.

\section{LA PINTURA, LA ILUSTRACIÓN Y LA FOTOGRAFÍA EN LOS PROGRAMAS DE FILOLOGÍA}

1. Puesto que los diversos géneros literarios se han desarrollado en cada lengua y su cultura a la par que las artes, debe aprovecharse la rica documentación visual que ilustra mucho de su literatura y sus períodos, ampliando así las perspectivas intelectuales y multidisciplinares del alumno, el rigor científico del curso y su amenidad en el aula.

Por ejemplo, las literaturas griega y latina nos ofrecen (aparte, por ejemplo, de las normas no verbales propuestas por Cicerón o Quintiliano para la oratoria) descripciones de los comportamientos no verbales (incluidos los silencios), así como de otras manifestaciones no verbales y no comportamentales, en poemas épicos griegos (ej., La Odisea) o latinos (ej., La Eneida), en la novela romana (ej., Satiricón, El asno de oro) y en el teatro griego (tragedias como Medea, Agamenón, comedias como Las nubes) y el romano (comedias como Los hermanos), de escasísimas acotaciones escénicas, pero muchos de cuyos comportamientos imaginamos en los diálogos verbales (aunque fácilmente erremos por su alejamiento histórico y cultural). Además, las descripciones textuales deben relacionarse con las representaciones visuales que en esas dos culturas constituyen documentos mudos, pero de gran dinamismo (ej., escenas representadas, por ejemplo, en los lekitos griegos, o en un jarrón camafeo romano como el por hoy llamado 'jarrón Bonhams', de entre el siglo I a.C. y el siglo I d.C.).

En períodos posteriores podemos enriquecer enormemente el estudio de sus textos literarios incluyendo habitualmente referencias a la pintura más realista a partir del XVIII, y luego la llamada de género o costumbrista (como hacía yo, en mi época de hispanista, al enseñar nuestro romanticismo y realismo pictóricos del XIX). Por ejemplo, Filología Inglesa, aumentaría la sensibilidad de sus futuros especialistas hacia cada época literaria al acompañar el análisis de sus obras con el de su típica pintura de género llamada anecdotal painting, como los detalladísimos documentos del entorno visual, para el XVIII, del satírico y moralizante William Hogarth (las series The Harlot's Progress, Mariage a la Mode y The Rake's Progress), y para la época victoriana o la de un Hardy nos adentramos en su mundo a través de las escenas de un Haynes King (ej., Jealousy and Flirtation) o Sir William Orchardson (ej., Mariage de Convenence, The First Cloud, de igual intención que escenas semejantes del ruso Pukierev). En Filología Eslava acudiremos a su 
costumbrismo pictórico y realismo social del XIX y XX de Pukierev, Riepin, Serov, Alvazovsky, Grigorevich, Ivanovich.

2. Pero no excluyamos nunca - por su valor 'cultural translatorio' - la obra de los ilustradores coetáneos de los escritores, como 'Phiz' (Dickens), José Luis Pellicer (Le Nabab, de Daudet), el gran Apeles Mestres (los Episodios Nacionales, de Galdós) u Oreste Vereisky (la tetralogía épica de Sholokhov El Don apacible).

3. También deben conocerse esas culturas y períodos a través de las mejores adaptaciones cinematográficas (importante tema en sí), por ejemplo: para Filología Eslava, la de la mencionada obra de Sholokhov, por Gerasimov (1957); para Filología Inglesa, las de Austen, las Brontë, Dickens, Hardy, y posteriores, como la de 1987, por John Huston, de The Dead, de Joyce, que en gran parte puede seguirse palabra por palabra con el libro, o la de 1939, de John Ford, de Grapes of Wrath, de Steinbeck.

4. Este estudio paralelo literatura-arte no debe dejar de aprovechar lo que significó la fotografía para ilustrar la literatura más realista, especialmente la reveladora obra testimonial estadounidense de fotógrafos como Dorothea Lange, Walker Evans, Gordon Parks o Arthur Rothstein para los autores del realismo, para los del regionalismo y naturalismo rurales, o para la Gran Depresión, desde Cather, Norris o Sinclair a Faulkner, Farrell, Steinbeck o Caldwell.

MATERIALES. Golder 1992; Gombrich 1972; Poyatos 1992: 237-360; 1994: Cap. 6; 2002a: Cap. 6; 2008: Cap. 4.5; 2002 b.

\section{REFERENCIAS BIBLIOGRÁFICAS}

GOLDER, Herbert (1992): "Visual Meaning in Greek Drama: Sophocles' Ajax and the Art of Dying", en Advancements in Nonverbal Communication: Sociocultural, Clinical, Esthetic and Literary Perspectives, Poyatos, F. (coord.), Amsterdam/Filadelfia, John Benjamins, 323-360.

GOMBRICH, E. H. (1972): "Action and expression in western art", en Non-Verbal Communication, Hinde, R.A. (coord.), Cambridge, Cambridge University Press, 373-394.

HOLOKA, James P. (1992: "Nonverbal communication and criticism of the classics: research opportunities", en Advancements in Nonverbal Communication: Sociocultural, Clinical, Esthetic and Literary Perspectives, Poyatos, F. (coord.), Amsterdam/Filadelfia, John Benjamins, 239-254.

LATEINER, Donald (1992): "Affect displays in the epic poetry of Homer, Vergil, and Ovid", en Advancements in Nonverbal Communication: Sociocultural, Clinical, Esthetic and Literary Perspectives, Poyatos, F. (coord.), Amsterdam/Filadelfia, John Benjamins, 255-269.

NEWBOLD, Ronald (1992): "Nonverbal communication in late Greek epic: Quintus of Smyrna, and Nonnus", en Advancements in Nonverbal Communication: Sociocultural, Clinical, Esthetic and Literary Perspectives, F. Poyatos (coord.), Amsterdam/Filadelfia, John Benjamins, 271-283. 
NEWBOLD, Ronald (1997): "Nonverbal communication and primary process in Roman verse satire", Quaderni Urbanitu di Cultura Classica 57(3), 107-118.

POYATOS, Fernando (1972): "Paralenguaje y kinésica del personaje novelesco: nueva perspectiva en el análisis de la narración", Revista de Occidente 113/114, 148-170.

POYATOS, Fernando (1975). "Gesture Inventories: Fieldwork Methodology and Problems", Semiotica 13(2), 199-227.

POYATOS, Fernando (1976). "Nueva perspectiva de la narración a través de los repertorios extraverbales del personaje", en Teoría de la novela, SanzVillanueva, S., Barbachano, C. (coord.), Madrid, S.G.E.L., 353-383.

POYATOS, Fernando (1986), "Nonverbal Categories as Personal and Cultural Identifiers: A Model for Social Interaction Research", en Iconicity: Essays on the Nature of Culture, Festschrift for Thomas A. Sebeok On his 65th Birthday, Bouissac, P., Herzfeld, M., Posner, R. (coord.), Tubinga, Stauffenburg Verlag, 469-525.

POYATOS, Fernando (1988): "Literary Anthropology: Toward a New Interdisciplinary Area", en Literary Anthropology: New Approches to People, Signs and Literature, Poyatos, ed. (coord.), Amsterdam/Filadelfia, John Benjamins, 3-49.

POYATOS, Fernando (1993): Paralanguage: A Linguistic and Interdisciplinary Interactive Speech and Sounds, Amsterdam/Filadelfia, John Benjamins.

POYATOS, Fernando (1994a): La comunicación no verbal, Vol. I: Cultura, lenguaje y conversación, Madrid, Ediciones Istmo.

POYATOS, Fernando (1994b): La comunicación no verbal, Vol. II: Paralenguaje, kinésica e interacción, Madrid, Ediciones Istmo.

POYATOS, Fernando (1994c): La comunicación no verbal, Vol. III: Nuevas perspectivas en novela y teatro y en su traducción, Madrid, Ediciones Istmo.

POYATOS, Fernando (1994d). "Paralenguaje y sonidos extrasomáticos en la novela: Perspectivas semiótico-comunicativas a través de los estudios de comunicación no verbal", en Semiótica(s): Homenaje a Greimas, Romera, J., Yllera, A., García-Monge, M (coord.), Madrid, Visor Libros, 141-155.

POYATOS, Fernando $\left(1996^{\mathrm{a}}\right)$. «La comunicación no verbal en el discurso y en el texto», Analecta Malacitana XIX (I), 67-85.

POYATOS, Fernando (1996b): "La lengua hablada como realidad verbal-no verbal: nuevas perspectivas", en Pragmática y gramática del español hablado. Actas del II Simposio de Español Hablado, Briz, A. et al. (coord.), Valencia, Libros Pórtico, 215-224.

POYATOS, Fernando (1996c): "La comunicación no verbal en las relaciones interpersonales y con el ambiente", en Actas: XVI Curso de Verano de San Roque, Vol. I, Vías Regias a lo Inconsciente, Cádiz, Universidad de Cádiz, 7-28.

POYATOS, Fernando (1997a): "El acto de lectura: su realidad verbal-no verbal", El Extramundi y los Papeles de Iria Flavia 11, 11-60. 
POYATOS, Fernando (1997b), "Aspects, Problems and Challenges of Nonverbal Communication in Literary Translation", en Nonverbal Communication in Translation, Poyatos, F. (coord.), Amsterdam/Filadelfia, John Benjamins, 1747.

POYATOS, Fernando (1998a), "El paralenguaje en el Quijote: inventario completo y bases para su estudio", Signa: Revista de la Asociación Española de Semiótica, 7, 293-318.

POYATOS, Fernando (1998b): "Los silencios en el discurso vivo y en la literatura: para el estudio realista del lenguaje y su entorno", Oralia: Análisis del discurso oral 1, 47-70.

POYATOS, Fernando (1999): "La kinésica en el Quijote: inventario completo y bases para su estudio", Signa:Revista de la Asociación Española de Semiótica 8, 281-326.

POYATOS, Fernando (2000): "New perspectives on intercultural interaction through nonverbal communication studies", Intercultural Communication Studies 12, 1-41.

POYATOS, Fernando (2001): "Escritor, personaje, lector, espectador, entorno: procesos semiótico-comunicativos en teatro y cine", El Extramundi y los Papeles de Iria Flavia 27, 9-52.

POYATOS, Fernando (2002a): Nonverbal Communication Across Disciplines, Volume I:Culture, Sensory Interaction, Speech, Conversation, Amsterdam/Filadelfia, John Benjamins.

POYATOS, Fernando (2002b): Nonverbal Communication Across Disciplines, Vol. II: Paralanguage, Kinesics, silence, personal and environmental interaction. Amsterdam/Filadelfia, John Benjamins.

POYATOS, Fernando (2002c): Nonverbal Communication Across Disciplines, Vol.III: Narrative Literature, Theater, Cinema, Translation. Amsterdam/Filadelfia, John Benjamins.

POYATOS, Fernando (2002d): "Anthropology/Psychology/Sociology", en Encyclopedia of Literature and Science, Gossen, P. (coord.), Westport/Londres: Greenwood Press, 13-20.

POYATOS, Fernando (2002e): "The nature, morphology and functions of gestures, manners and postures as documented by creative literature". Gesture 2:1, 111129.

POYATOS, Fernando (2003): "Los comportamientos no verbales como contexto y entorno del discurso oral", Oralia: Análisis del discurso oral 5, 283-307.

POYATOS, Fernando (2004): "Nuevas perspectivas lingüísticas en comunicación no verbal", en Les fronteres del llenguatge: lingüistica i comunicació no verbal, Payrató, L. (coord.), Barcelona, Universidad de Barcelona, 57-91.

POYATOS, Fernando (2005): "La transcripción integral de la conversación en el estudio del habla verbal-no verbal andaluza", en Aspectos de la lengua y litera- 
tura y su enseñanza en Andalucía, Prado Aragonés, J. y de las Heras Borrero, J. (coord.), Huelva, GEU Editorial, 131-150.

POYATOS, Fernando (2008): Textual Translation and Live Translation: The Total Experience of Nonverbal Communication in Literature, Theater and Cinema. Amsterdam/Filadelfia: John Benjamins.

POYATOS, Fernando (2010a): "Leyendo a Juan Ramón Jiménez a la luz de los estudios de comunicación no verbal", en Estudios andaluces de lengua y literatura, Galloso, M. V. (coord.), Huelva: GEU Editorial, 193-218.

POYATOS, Fernando (2010b): "La formación académica sobre los libros y la lectura a través de los estudios de comunicación no verbal", DILL Didáctica (Lengua y Literatura), 22, 277-296.

POYATOS, Fernando (2010c): "El incierto destino del discurso verbal-no verbal en teatro y cine: el espectador ante la traducción lingüística e intercultural", Oralia: análisis del discurso oral, 215-233.

POYATOS, Fernando (2013): "Body Gestures, Manners and Postures in Literature", en Body-Language-Communication. Handbooks of Linguistics and Communication Science, Müller, C. Ricke, E. Cienki, A., McNeill, D. (coord.), Berlin/Nueva York, Mouton de Gruyter (en prensa).

VERMEER, Hans J. (1992): "Describing nonverbal behavior in the Odyssey: scenes and verbal frames as transalation problems", en Advancements in Nonverbal Communication: Sociocultural, Clinical, Esthetic and Literary Perspectives, Poyatos, F. (coord.), Amsterdam/Filadelfia, John Benjamins, 285-299. 